US Army Corps

of Engineers ${ }_{\circledast}$

Engineer Research and

Development Center

\title{
Improved Vehicle Mobility by Using Terrain Surfacing Systems
}

John F. Rushing and Daniel E. Harder

April 2020 
The U.S. Army Engineer Research and Development Center (ERDC) solves the nation's toughest engineering and environmental challenges. ERDC develops innovative solutions in civil and military engineering, geospatial sciences, water resources, and environmental sciences for the Army, the Department of Defense, civilian agencies, and our nation's public good. Find out more at www.erdc.usace.army.mil.

To search for other technical reports published by ERDC, visit the ERDC online library at http://acwc.sdp.sirsi.net/client/default. 


\title{
Improved Vehicle Mobility by Using Terrain Surfacing Systems
}

John F. Rushing and Daniel E. Harder

Geotechnical and Structures Laboratory

U.S. Army Engineer Research and Development Center

3909 Halls Ferry Road

Vicksburg, MS 39180-6199

Final report

Approved for public release; distribution is unlimited.

\author{
Prepared for U.S. Army \\ Washington, DC 20314 \\ Under Project BL8, "Power Projection in A2/AD Environments"
}




\section{Abstract}

Even for military vehicles designed with superior off-road capabilities, problematic soil conditions can impede mobility, particularly when many vehicles need to traverse the same path. Loose sands with little shear strength or wet silts or clays with little bearing capacity can deform rapidly under traffic. U.S. Army Engineer Research and Development Center researchers conducted field testing over several terrain conditions to measure performance of terrain surfacing systems designed to improve vehicle mobility. Soil conditions included poorly-graded sand, medium-strength silt, weak marsh, and two different slope conditions. Five different terrain surfacing, or matting systems, were tested that included four commercial variants and one U.S. government design. All testing took place at the ERDC Ground Vehicle Terrain Surfacing Test Facility in Vicksburg, Mississippi. Military test vehicles included a Marine Tactical Vehicle Replacement, Common Bridge Transporter, and M1 Abrams tank. Results from the testing showed that all matting systems provided notable improvement in the number of allowable vehicle passes over soft sands. Results varied for the different systems over weaker soils, with performance improved for those matting systems having thicker and stiffer panels. However, improved performance among matting systems came with a sacrifice of increased logistical burden. Data presented herein include detailed site characteristics and soil deformation as a function of traffic.

DISCLAIMER: The contents of this report are not to be used for advertising, publication, or promotional purposes. Citation of trade names does not constitute an official endorsement or approval of the use of such commercial products. All product names and trademarks cited are the property of their respective owners. The findings of this report are not to be construed as an official Department of the Army position unless so designated by other authorized documents. 


\section{Contents}

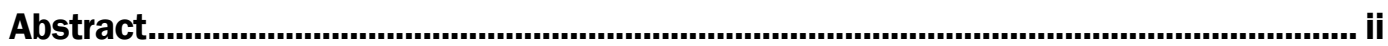

Figures and Tables.....................................................................................................................

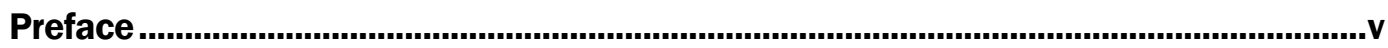

1 Introdution ............................................................................................................... 1

2 Objectives and scope ...................................................................................... 1

3 Matting System ................................................................................................................ 2

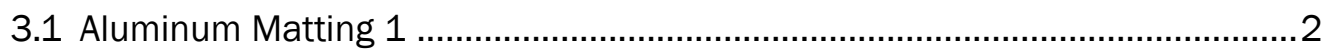

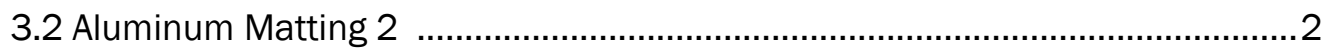

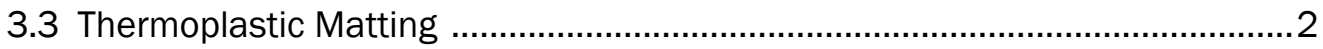

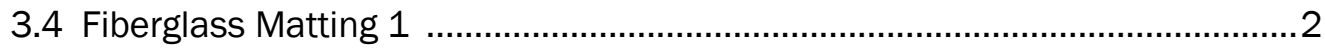

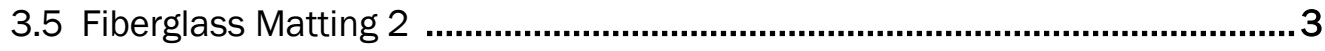

3.6 Summary of mat properties …...................................................................... 3

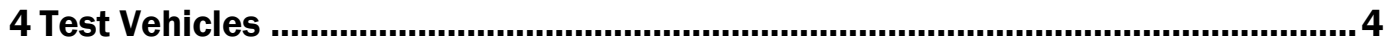

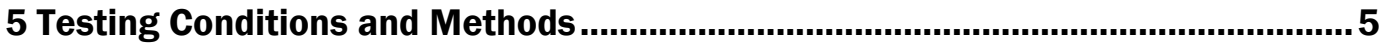

6 Results and Analysis .................................................................................... 8

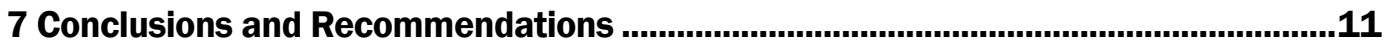

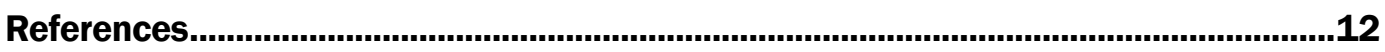

Report Documentation Page 


\section{Figures and Tables}

\section{Figures}

Figure 1. Matting systems evaluated for river bank stabilization. ....................................... 3

Figure 2. Test vehilcels used in this study.................................................................... 5

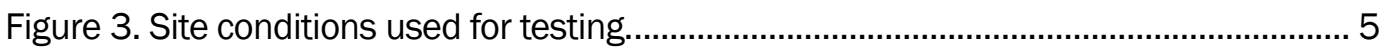

Figure 4. Testing slopes with mud placed on mats........................................................... 7

Figure 5. Representative cross section profile data for Fiberglass Matting 1.................... 10

\section{Tables}

Table 1. Summary of mat properties.................................................................................. 3

Table 2. Summary of test vehicle properties. .................................................................. 4

Table 3. Summary of mat test results. ................................................................................. 8 


\section{Preface}

This study was originally conducted for the U.S. Army under Project BL8, "Power Projection in A2/AD Environments." The technical monitor was Mr. Nicholas Boone.

The work was performed by the Airfields and Pavements Branch (APB) of the Engineering Systems and Materials Division (ESMD), U.S. Army Engineer Research and Development Center, Geotechnical and Structures Laboratory (ERDC-GSL). At the time of publication of this Miscellaneous Paper, Dr. Timothy W. Rushing was Chief, APB; Mr. Justin S. Strickler was Chief, ESMD; and Ms. Pamela G. Kinnebrew was the Technical Director for Military Engineering. The Deputy Director of ERDC-GSL was Mr. Charles W. Ertle II, and the Director was Mr. Bartley P. Durst.

The authors would like to acknowledge the Army Program Executive Office Combat Support and Combat Service Support, Product Manager Bridging for financial support in conducting these tests. The Mississippi Army National Guard and the Army 7th Transportation Brigade are thanked for providing test vehicles and support.

The Commander of ERDC was COL Teresa A. Schlosser and the Director was Dr. David W. Pittman. 


\title{
IMPROVED VEHICLE MOBILITY BY USING TERRAIN SURFACING SYSTEMS
}

\author{
John F. Rushing and Daniel E. Harder ${ }^{\mathrm{a}}$ \\ ${ }^{a}$ U.S. Army Engineer Research and Development Center, 3909 Halls Ferry Road, Vicksburg, MS 39180, USA \\ john.f.rushing@usace.army.mil, daniel.e.harder@usace.army.mil
}

\begin{abstract}
Even for military vehicles designed with superior off-road capabilities, problematic soil conditions can impede mobility, particularly when many vehicles need to traverse the same path. Loose sands with little shear strength or wet silts or clays with little bearing capacity can deform rapidly under traffic. Researchers at the U.S. Army Engineer Research and Development Center conducted field testing over several different terrain conditions to measure performance of terrain surfacing systems designed to improve vehicle mobility. Soil conditions included poorlygraded sand, medium-strength silt, weak marsh, and two different slope conditions. Five different terrain surfacing, or matting systems, were tested that included four commercial variants and one U.S. government design. All testing took place at the ERDC Ground Vehicle Terrain Surfacing Test Facility in Vicksburg, Mississippi, USA. Military test vehicles included a Marine Tactical Vehicle Replacement, Common Bridge Transporter, and M1 Abrams tank. Results from the testing showed that all matting systems provided notable improvement in the number of allowable vehicle passes over soft sands. Results varied for the different systems over weaker soils, with performance improved for those matting systems having thicker and stiffer panels. However, improved performance among matting systems came with a sacrifice of increased logistical burden. Data presented herein include detailed site characteristics and soil deformation as a function of traffic.
\end{abstract}

\section{Introduction}

The U.S. Army conducts wet gap crossings using temporary floating bridges. These floating bridges allow vehicles to quickly cross rivers away from existing bridges, or when existing bridges are damaged or unable to support military traffic. These bridges often must be placed at river banks with weak soils, which creates mobility problems for some vehicles, especially after repeated traffic. Standard construction equipment is often used to grade and compact river banks for access/egress. In some cases, crushed stone or gravel is placed atop the area to provide additional support. However, in expeditionary military operations, access to these resources or time constraints often limit acceptable techniques for stabilizing river banks. In these cases, temporary matting systems offer a reusable, rapid capability for ensuring vehicle mobility (Floyd, 2017; Rushing et al., 2007; Rushing et al., 2012; Rushing et. al, 2009; Rushing and Torres, 2007; Santoni et al., 2001).

\section{Objective and scope}

The objective of this study was to determine potentially suitable matting systems that are currently available, either commercial-off-the-shelf systems or government owned systems, and to evaluate them for use under military traffic on soil conditions potentially encountered during river crossings. Five matting systems were selected for testing. The evaluation took place at the U.S. Army Engineer Research and Development Center (ERDC) Ground Vehicle Terrain Surfacing Test Facility in Vicksburg, MS, from 1 to 25 August 2017. During this period, ERDC evaluated the five matting systems using a range of military vehicles on various soil and site conditions. ERDC constructed a test track, with five different soil and site conditions, specifically chosen to replicate realistic riverbanks and to isolate likely matting failure mechanisms. These sites were sand, silt, marsh, and bare slopes having 10-percent and 25-percent grades. Matting systems were placed on these conditions and then trafficked with wheeled and tracked vehicles to simulate the crossing of an Armored Brigade Combat Team (ABCT). 


\section{Matting Systems}

\subsection{Aluminum Matting 1}

Aluminum matting 1 (Figure 1a) is a rolled matting system comprised of aluminum planks approximately $4.3-\mathrm{m}$ wide and $23-\mathrm{cm}$ long. These planks lock together using a hinge that allows the sections to roll up onto a truckmounted launching system. The launching system, which is integrated into a standard flat rack, can be picked up by a Palletized Loading System (PLS), Common Bridge Transporter (CBT), or other military vehicles that can load such pallets. The length of matting on the launcher depends on the weight capacity of the vehicle being used, but is typically 15 to $30 \mathrm{~m}$. For this study, the launcher was delivered with approximately $45 \mathrm{~m}$ of matting. Each plank is made from a hollow box with small vertical supports inside to provide strength. The ends are capped to prevent debris from entering the cavities. The surface is smooth, bare aluminum with small ridges every few centimeters to provide traction. Planks are held together with a long H-shaped rod that slides inside of $\mathrm{C}$-shaped grooves on each side of the adjoining planks. Small bolts prevent this H-shaped rod from sliding out. On flat surfaces, the matting simply sits atop the ground; the system has a set of anchors for use on slopes or when lateral movement is a concern. If the path needs to be extended, mats can be placed end to end and the planks locked together. If the path needs to be widened, mats are placed next to each other but are not connected.

\subsection{Aluminum Matting 2}

Aluminum matting 2 (Figure $1 \mathrm{~b}$ ) is a rolling matting system comprised of aluminum planks approximately $4.6-\mathrm{m}$ wide and $23-\mathrm{cm}$ long. These planks lock together using a hinge that allows the sections to roll up onto a truck mounted launching system. The launching system is compatible with the same types of vehicles as Aluminum matting 1 . The length of matting on the launcher depends on the weight capacity of the vehicle being used, but is typically 15 to $30 \mathrm{~m}$. The system used in this study was supplied with approximately $30 \mathrm{~m}$ of matting. The entire plank is anodized and colored grayish-green. Planks are locked together at the end with a small latch that prevents the planks from sliding out. Also included in the system are planks half the width of the roadway, which makes it easier to join and separate long stretches of matting. On flat surfaces, the matting simply sits atop the ground; the system has a bracket and set of anchors for use on slopes or when lateral movement is a concern. If the path needs to be extended, mats can be placed end to end and the planks locked together. If the path needs to be widened, mats are placed next to each other but are not connected. The mat can be placed with either side up with no change in driving characteristics.

\subsection{Thermoplastic Matting}

Thermoplastic mats (Figure 1c) are large, heavy-duty, panels measuring approximately $2.4 \mathrm{~m}$ by $4.3 \mathrm{~m}$ with a useable surface of $2.1 \mathrm{~m}$ by $4 \mathrm{~m}$ and $0.3 \mathrm{~m}$ of overlap and underlap around the edges. They are placed in a grid and joined together with locking pins that drop into rectangular grooves and twist 90 degrees to lock in place. Each panel weighs approximately $476 \mathrm{~kg}$ and must be placed with a forklift or other material handling equipment. The surface is smooth plastic with ridges added for traction. Each panel is hollow with an internal structure to provide support and is sealed to prevent water or debris from entering the cavities.

\subsection{Fiberglass Matting 1}

The fiberglass matting 1 system (Figure 1d) is comprised of square fiberglass panels arranged in a grid to create a driving surface. This matting system was held together in place with $1.2-\mathrm{m}$ screw anchors, which were installed through holes in adjoining mats. Each mat has a useable surface of $1.8 \mathrm{~m}$ by $1.8 \mathrm{~m}$ with $20 \mathrm{~cm}$ of overlap or underlap on each side, providing a logistics footprint of $2 \mathrm{~m}$ by $2 \mathrm{~m}$. Holes are located in the corners to allow anchors to be placed and to connect the mats. Each panel weighs approximately $54 \mathrm{~kg}$ and can be carried and emplaced by two people. The top surface of the mat has an aggressive diamond-shaped embossed pattern for traction. The mats are placed by hand, and the screw anchors are installed with a hydraulic impact drill and 50-mm socket. 


\subsection{Fiberglass Matting 2}

Fiberglass matting 2 (Figure 1e) is a lightweight mat used for rapid ground improvement over medium-strength sands and soils. The mat consists of fiberglass measuring $4.3 \mathrm{~m}$ by $18.3 \mathrm{~m}$ with an egg crate/waffle pattern. The mat can be rolled up and deployed with a squad of soldiers but is most easily placed using a forklift and one to two people. A ratchet strap or rope holds the roll together while in storage. If a longer or wide path is required, mats are placed next to each other, but they are generally not connected to each other. Short rebar style anchors, which are approximately $0.46-\mathrm{m}$ long with a flat " $\mathrm{T}$ " head, can be used to hold the mat in place by hammering them through reinforced holes along the edge of the mat. The mat has an aggressive texture added to the surface in addition to the wavy structure of the mat. Each mat weighs about $438 \mathrm{~kg}$.

\subsection{Summary of mat properties}

Table 1 contains a property comparison of all matting systems. The properties in Table 1 reference mats only and do not include the weight of anchors, launchers, or material handling equipment required. Figure 1 shows each of the matting systems used in this study.

Table 1. Summary of mat properties.

\begin{tabular}{llccc}
\hline Mat system & Material & $\begin{array}{l}\text { Single panel } \\
\text { area }\left(\mathbf{m}^{\mathbf{2}}\right)\end{array}$ & $\begin{array}{l}\text { Panel weight } \\
\mathbf{( k g )}\end{array}$ & $\begin{array}{l}\text { Unit weight } \\
\left(\mathbf{k g} / \mathbf{m}^{\mathbf{2}}\right)\end{array}$ \\
\hline Aluminum 1 & Aluminum & 0.9 & 24 & 26.7 \\
Aluminum 2 & Aluminum & 1.0 & 39 & 39.0 \\
Thermoplastic & Plastic & 8.5 & 476 & 56.0 \\
Fiberglass 1 & Fiberglass & 3.3 & 54 & 16.7 \\
Fiberglass 2 & Fiberglass & 78.0 & 438 & 5.6 \\
\hline
\end{tabular}

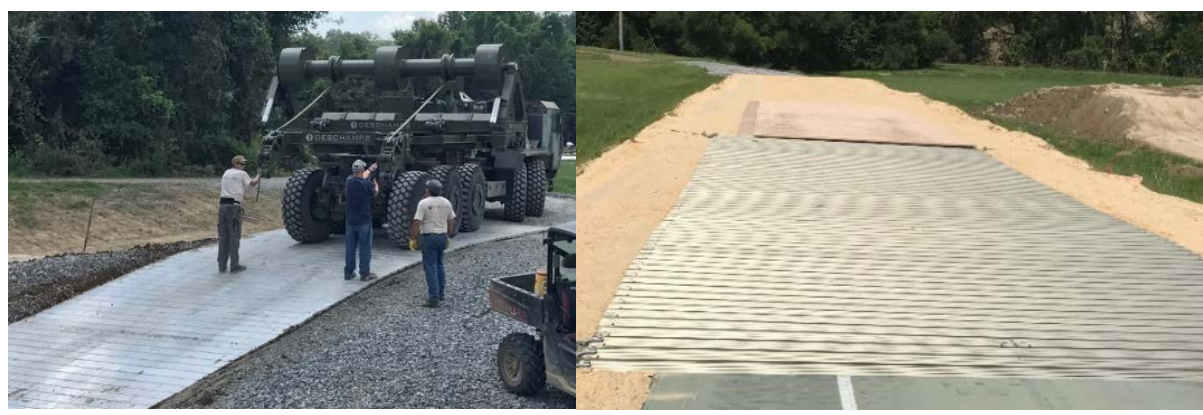

(a) Aluminum matting 1 (b) Aluminum matting 2

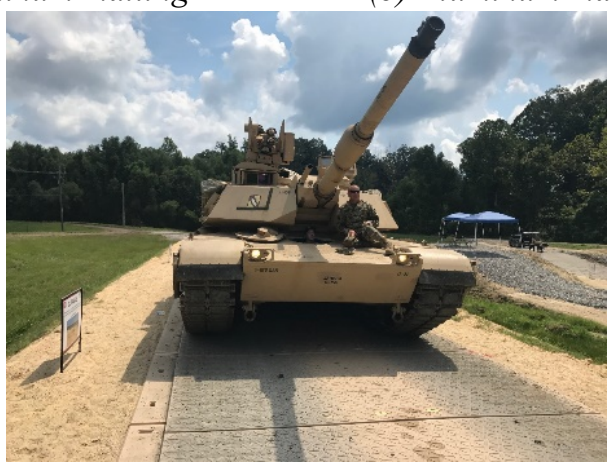

(c) Thermoplastic matting 


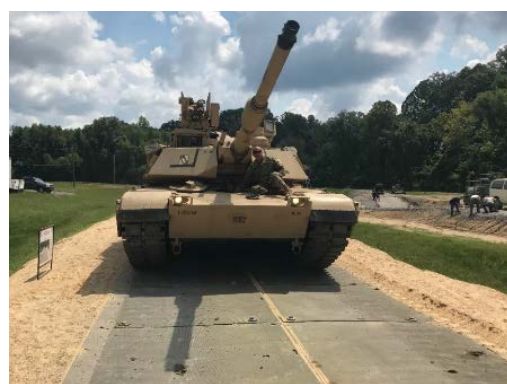

(d) Fiberglass matting 1

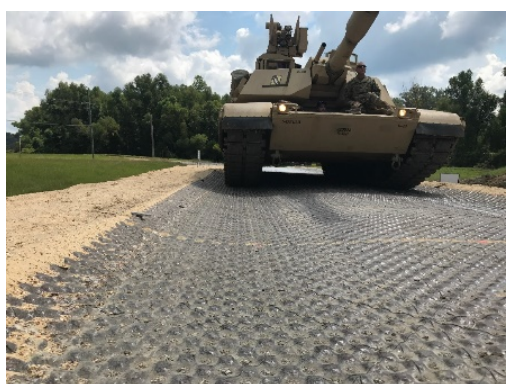

(e) Fiberglass matting 2

Figure 1. Matting systems evaluated for river bank stabilization.

\section{Test Vehicles}

For trafficking purposes, three vehicles were used during testing, i.e., the Marine Tactical Vehicle Replacement (MTVR), CBT, and M1 Abrams tank (M1). The MTVR was used for traffic over sand and medium-strength soils, while the CBT was used for traffic over slopes and marsh because of the specific test vehicle's better traction and $8 \times 8$ drive capability. The M1 was used on portions of all tests. Table 2 provides general characteristics of the test vehicles, and Figure 2 shows each of the three test vehicles.

Table 2. Summary of test vehicle properties.

\begin{tabular}{llcccl}
\hline Vehicle & $\begin{array}{l}\text { Wheeled/ } \\
\text { tracked }\end{array}$ & $\begin{array}{l}\text { Test weight } \\
(\mathbf{k g})\end{array}$ & $\begin{array}{l}\text { No. of } \\
\text { axles }\end{array}$ & $\begin{array}{l}\text { Avg. axle } \\
\text { weight (kg) }\end{array}$ & $\begin{array}{l}\text { Avg. ground } \\
\text { pressure (kPa) }\end{array}$ \\
\hline MTVR & Wheeled & 20,230 & 3 & 6,740 & 240 \\
CBT & Wheeled & 26,400 & 4 & 6,600 & 450 \\
M1 & Tracked & 64,400 & N/A & N/A & 75 \\
\hline
\end{tabular}

\section{Medium Tactical Vehicle Replacement (MTVR)}

The MTVR (Figure 2a) is a 3-axle, medium cargo vehicle used by the U.S. Marine Corps with a capacity of 9.1 tonnes. Its empty weight is $13,880 \mathrm{~kg}$. The loaded weight during testing was $20,230 \mathrm{~kg}$, and tire pressure was maintained at $240 \mathrm{kPa}$. This vehicle was used for all testing on sand and on medium-strength soil for this effort.

\section{Common Bridge Transporter (CBT)}

The CBT (Figure 2b) is a 4-axle, heavy cargo vehicle used by the U.S. Army with a nominal capacity of 9.1 tonnes. A CBT A2 model was used for this test. The CBT A2's empty weight was 17,330 kg. Its loaded weight for testing was $26,400 \mathrm{~kg}$, and the tire pressure was maintained at $450 \mathrm{kPa}$. This vehicle was used for all testing across the sloped and marsh test sections in its normal and in its $8 \times 8$ drive settings.

\section{M1 Abrams}

The M1A2 Abrams (Figure 2c) main battle tank is a heavy, armored tracked vehicle with a 120-mm canon. Reported weight during testing was $64,400 \mathrm{~kg}$; however, actual vehicle weight was not measured. Its ground pressure is approximately $75 \mathrm{kPa}$. This vehicle was used as the tracked vehicle for all test sections. 


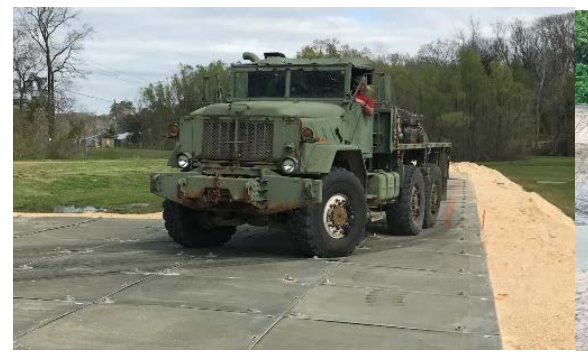

(a) MTVR

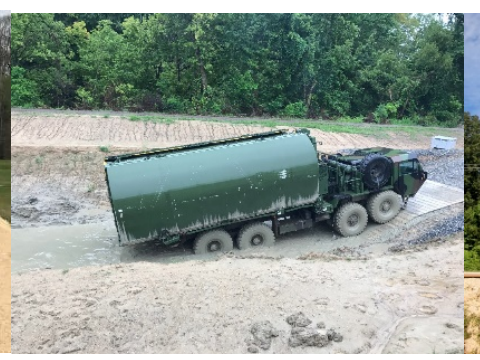

(b) $C B T$

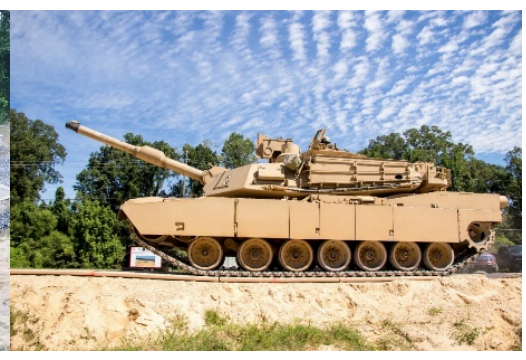

(c) $M 1$

Figure 2. Test vehicles used in the study.

\section{Testing Conditions and Methods}

\section{Site conditions}

Test conditions were specifically designed to represent a range of potentially problematic soils where matting would be required to support a large number of military ground crossings. These included varying soil types, strengths, and slopes. Figure 3 shows each of the site conditions used for testing. The following sections describe the test conditions used in this study.

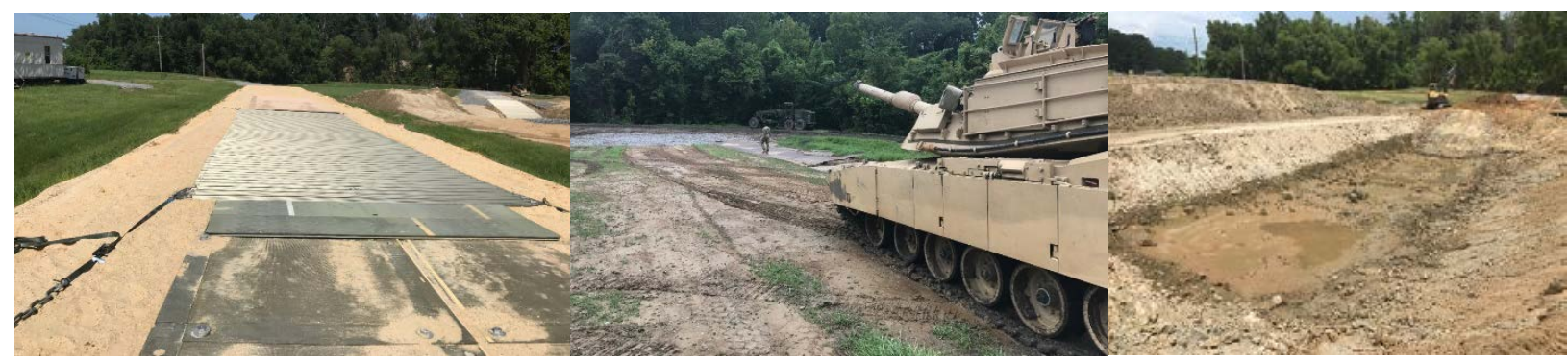

(a) Sand road

(b) medium-strength soil

(c) marsh

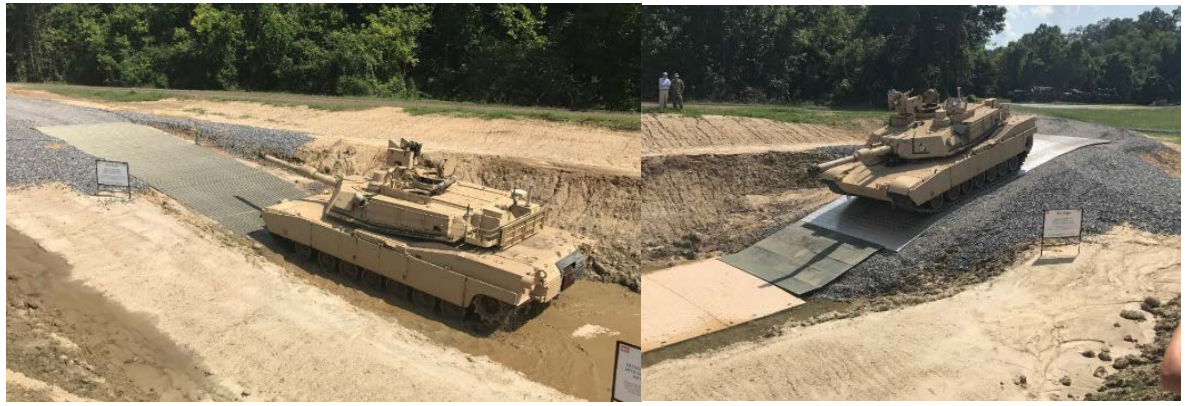

(d) 10-percent grade slope

(e) 25-percent grade slope

Figure 3. Site conditions used for testing.

\section{Sand}

The sand test area (Figure 3a) was prepared using a local concrete sand classified as poorly graded sand (SP) by the Universal Soils Classification System (USCS). This material is cohesionless, poorly graded, and provides adequate compressive strength but little shear strength. These properties present difficulty when crossing large numbers of ground vehicles due to accumulated rutting that develops.

The sand test area was prepared by placing the material from dump trucks over the native ground. No compaction was performed during placement. The material was placed in a straight line approximately $91-\mathrm{m}$ long and $5.5-\mathrm{m}$ wide to facilitate testing all systems simultaneously. The depth of sand was approximately $1.2 \mathrm{~m}$ to 
accommodate all of the anchor systems used with the mats. The sand was bladed smooth using a skid steer loader and bucket attachment prior to mat placement.

\section{Medium-strength soil}

The medium-strength soil test area (Figure 3b) used the native material at the test site which classified as lean silt (ML) according to the USCS. Prior to testing, a grader removed the upper 3 to $5 \mathrm{~cm}$ of soil and vegetation. The resulting bare soil consisted of a clayey silt with moderate cohesion and bearing capacity. This type of soil experiences difficulty supporting large numbers of ground vehicles due to rutting developed from the lack of bearing capacity. To ensure no significant strength changes existed between individual test sites, soil strength measurements were performed within one day of initiating traffic testing on each item.

\section{Marsh}

The marsh test area (Figure 3c) represented the weakest soil conditions and areas that may exist in low lying floodplains or coastal tidal regions where matting would be essential for wheeled vehicle crossings. To prepare the test area, a pit was excavated beneath the grade of the field site to a depth of approximately $2.4 \mathrm{~m}$. This depth was the water table due to a surrounding lake. The soil at the bottom of the pit classified as lean clay (CL) according to the USCS. The pit was approximately 5-m wide and 30-m long with sloped edges for stability. A sump pump was used to dewater the pit prior to any testing.

\section{Slopes}

Slope testing was included in this study to understand the matting system's ability to provide traction when traversing various grades. River crossings are expected to include access/egress conditions of varying slopes. For this study, slopes of 10-percent (Figure 3d) and 25-percent grades (Figure 3e) were used as benchmarks for assessing traction on the matting. The structural integrity of the matting over various soil strengths was characterized along the flat surfaces; the slopes were only used for observing traction. The marsh test area was used as the slope testing area, because it naturally required grades to exit the pit. Because a need existed to eliminate soil strength from this portion of the study and because the site conditions needed to be maintained in good condition, the slopes were covered with crushed limestone to provide a sound foundation for laying the mats.

Traction on the matting was expected to be influenced by the absence or presence of water and soil that was deposited on the mat surfaces during crossings. To understand the effects of these conditions, crossings were conducted in a dry and muddy condition. The dry condition was observed during the initial crossings after the mats were first laid. After this condition was observed, a muddy condition was created by placing a layer of soft mud across the full width of the mat, $0.3-\mathrm{m}$ thick and $5.5-\mathrm{m}$ long from the bottom of the mat (Figure 4). The mud was prepared by mixing local soil with water until a consistency existed that would represent that of approximately 15cm-slump concrete mixture. The mud was placed onto the mats using a skid steer loader and bucket attachment. 


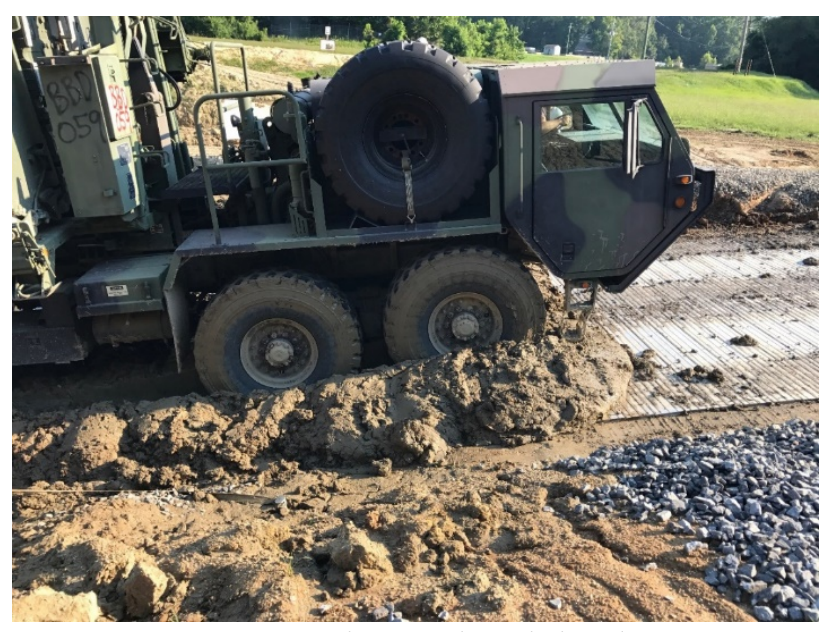

Figure 4. Testing slopes with mud placed on mats.

\section{Data Collection}

Prior to installing matting systems, soil strength was measured using a Dynamic Cone Penetrometer (DCP). Throughout testing the surface elevation was measured by rod and level surveys. The primary purpose of collecting these data was to document the actual field conditions of the ground surface and to measure deformation that occurred with accumulating traffic.

\section{Soil strength measurements using Dynamic Cone Penetrometer}

The DCP is a hand-held portable penetrometer device designed to penetrate pavement layers to a depth of 800-mm with a 20 -mm-diameter cone. The cone is attached to a $16-\mathrm{mm}$-diameter steel rod that is driven into the ground using an 8-kg hammer that is raised and lowered by hand. Testing consists of using the free-falling hammer to strike the cone causing the cone to penetrate the base or subgrade soil and then measuring the penetration per blow in $\mathrm{mm}$ /blow. This measurement denotes the stiffness of the tested material with a smaller number indicating a stiffer material. The penetration rate (PR) is used to correlate DCP measurements to California Bearing Ratio, which provides estimates of soil strength using Equation 1. The CBR ratio is a range from 1 to 100 with higher numbers indicating greater bearing capacity. The DCP was used in this test to document strength properties of the soil for comparing matting performance.

$$
\mathrm{CBR}=292 / \mathrm{PR} 1.12
$$

\section{Rod and level elevation surveys}

The purpose of the matting systems tested in this study were to provide sufficient traction for vehicles to traverse slopes and to spread loads from ground vehicles to minimize rutting in the soil. To measure the benefit of minimizing rutting, rod and level elevation surveys were performed in the longitudinal direction (in the wheel path) and the transverse direction across the mats at various locations. Elevations were recorded to the nearest $0.3 \mathrm{~cm}$ and normalized using a permanent benchmark as a reference point. A longitudinal profile was taken at 0.3-m increments along the vehicle's left wheel path. Additionally, three cross-section profiles were taken at 0.3 -m increments at the center of each matting section and $4.6 \mathrm{~m}$ on either side of the center point. During cross-section profile measurements, the left wheel path was loaded with $1,800 \mathrm{~kg}$ of lead weights to attempt to deflect the matting to the surface of the soil. Elevation surveys provide overall indication of the structural support provided by each matting system. Excessive permanent deformation is undesirable as it hinders traffickability. 


\section{Results and Analysis}

\section{Summary of vehicle traffic}

Not all mat systems were tested in every condition due to site conditions or due to time constraints related to the use of borrowed test vehicles. In most cases, the systems that were not tested on certain items were because they were not designed to meet the performance expectations. Discussion of matting performance on the sand and mediumstrength soil conditions are described below. Detailed discussion of the marsh and slope test portions are not discussed in detail but summarized in Table 3 along with each condition that was tested during the study.

Table 3. Summary of mat test results.

\begin{tabular}{|c|c|c|c|c|c|}
\hline & $\begin{array}{l}10 \% \text { Slope } \\
\text { covered in mud }\end{array}$ & $\begin{array}{l}25 \% \text { Slope } \\
\text { covered in mud }\end{array}$ & Marsh & $\begin{array}{l}\text { Medium } \\
\text { silt/clay }\end{array}$ & Sand \\
\hline \multirow[t]{2}{*}{$\begin{array}{l}\text { Aluminum } \\
\text { Matting } 1\end{array}$} & $\begin{array}{l}10 \text { passes CBT; } \\
5 \text { passes M1. }\end{array}$ & $\begin{array}{l}10 \text { passes CBT; } \\
5 \text { passes M1. }\end{array}$ & $100^{*}$ passes & 500 passes & 1,000 passes \\
\hline & $\begin{array}{l}\text { Required all } \\
\text { wheel drive for } \\
\text { first } 8 \text { passes. } \\
\text { Last two passes } \\
\text { were with rear } \\
\text { wheel only. No } \\
\text { issues for M1 }\end{array}$ & $\begin{array}{l}\text { Required all } \\
\text { wheel drive. } \\
\text { When stopping on } \\
\text { mat, CBT would } \\
\text { slide backwards. } \\
\text { No issues for M1 }\end{array}$ & $\begin{array}{l}\text { Mat accumulated } \\
\text { large quantities of } \\
\text { mud on surface, } \\
\text { immobilizing } \\
\text { vehicle after } 66 \\
\text { passes. Traffic } \\
\text { ceased after } \\
\text { objective was met. }\end{array}$ & $\begin{array}{l}\text { No } \\
\text { observable } \\
\text { rutting }\end{array}$ & $\begin{array}{l}\text { No observable } \\
\text { rutting }\end{array}$ \\
\hline \multirow[t]{2}{*}{$\begin{array}{l}\text { Aluminum } \\
\text { Matting } 2\end{array}$} & $\begin{array}{l}10 \text { passes CBT; } \\
5 \text { passes M1. }\end{array}$ & $\begin{array}{l}10 \text { passes CBT; } \\
5 \text { passes M1. }\end{array}$ & 200 passes & 500 passes & 1,000 passes \\
\hline & $\begin{array}{l}\text { Required all } \\
\text { wheel drive for } \\
\text { first } 3 \text { passes, but } \\
\text { only rear drive } \\
\text { for final seven. } \\
\text { No issues for M1 }\end{array}$ & $\begin{array}{l}\text { Required all } \\
\text { wheel drive for } \\
\text { first } 3 \text { passes. } \\
\text { Final } 7 \text { passes } \\
\text { with rear wheel } \\
\text { drive only. No } \\
\text { issues for M1. }\end{array}$ & $\begin{array}{l}\text { Some bending, but } \\
\text { withstood traffic. }\end{array}$ & $\begin{array}{l}\text { Slight } \\
\text { rutting and } \\
\text { bending of } \\
\text { mat }\end{array}$ & $\begin{array}{l}\text { No observable } \\
\text { rutting }\end{array}$ \\
\hline \multirow[t]{2}{*}{$\begin{array}{l}\text { Thermoplastic } \\
\text { Matting }\end{array}$} & $\begin{array}{l}10 \text { passes CBT; } \\
5 \text { passes M1. }\end{array}$ & $\begin{array}{l}10 \text { passes CBT; } \\
5 \text { passes M1. }\end{array}$ & 300 passes & Did not test & 1,000 passes \\
\hline & $\begin{array}{l}\text { Started with mat } \\
\text { clean (no mud } \\
\text { added). Required } \\
\text { only rear-wheel } \\
\text { drive. }\end{array}$ & $\begin{array}{l}\text { Started with mat } \\
\text { clean (no mud } \\
\text { added). Required } \\
\text { all-wheel drive } \\
\text { each time. }\end{array}$ & $\begin{array}{l}\text { No issues } \\
\text { supporting loads }\end{array}$ & & $\begin{array}{l}\text { No observable } \\
\text { rutting }\end{array}$ \\
\hline $\begin{array}{l}\text { Fiberglass } \\
\text { Matting } 1\end{array}$ & Did not test & Did not test & Did not test & 300 passes & 1,000 passes \\
\hline \multirow{2}{*}{$\begin{array}{l}\text { Fiberglass } \\
\text { Matting } 2\end{array}$} & Did not test & Did not test & Did not test & 133 passes & 1,000 passes \\
\hline & & & & $\begin{array}{l}\text { Mat } \\
\text { destroyed by } \\
\text { tearing }\end{array}$ & $\begin{array}{l}\text { Approx. 3- } \\
5 \text { in. rutting }\end{array}$ \\
\hline
\end{tabular}




\section{DCP measurements}

DCP measurements were recorded to provide a measure of soil strength at the different site conditions. For soils such as a loose sand, the DCP measurements are expected to remain consistent with time as the moisture content does not widely vary. The fluctuation in moisture content was expected to cause some changes in the mediumstrength soil, so measurements were taken after grading the surface and then prior to placing mats and applying traffic. Collecting DCP measurements in the marsh test area was difficult because the surface of the soil was unable to support the weight of the DCP. In each case, the readings taken from testing were converted to CBR values which are reported herein.

Along the sand road, DCP measurements were taken at 30-m spacing for a total of five locations. As common with loose sands, the converted CBR values increase with depth as a result of confinement while the nearsurface CBR values are very low due to a lack of confinement. In general, the soil at depths of 15 to $46 \mathrm{~cm}$ has CBR values ranging from 8 to 20 , typical for this soil type.

In the medium-strength silt test area, the surface soil exhibited higher CBR values than the underlying soil due to the surface drying in the hot summer temperatures. While the upper 10-20 cm had CBR values in the 10 to 20 range, the material below was more consistent and measured around 3 to 5 CBR. This weaker soil was where deformations occurred under heavy vehicle traffic.

DCP measurements were attempted in the marsh soil condition. These readings indicated that the CBR values were 1 to 2 in the upper 20 to $30 \mathrm{~cm}$, with deeper soil having increased soil strength up to $5 \mathrm{CBR}$.

\section{Rod and level elevation surveys}

Elevation surveys were performed using a rod and level on the surface of the mats placed on the sand and mediumstrength test areas to measure permanent deformation that may have occurred with traffic testing. Additionally, based on limited timeframe for testing and past exceptional performance, thermoplastic matting was not trafficked over the medium-strength soil. Its performance exceeds that of the systems evaluated for that soil condition.

\section{Sand test area}

Figure 5 shows the cross-section profiles for the Fiberglass matting 1 on the sand test area for varying traffic intervals. These data are typical of cross section profiles showing accumulating rutting with increased vehicle traffic. Remaining data are not presented in this paper for brevity but can be found in Harder and Rushing (2018).

The cross-section profile shows that additional soil formed upheaval in the center of the mat between the wheel paths and along the edges. These data show approximately $4.5 \mathrm{~cm}$ of total difference between the highest and lowest elevations. Overall, the Fiberglass matting 1 successfully sustained 1,000 combined passes of vehicle traffic. 


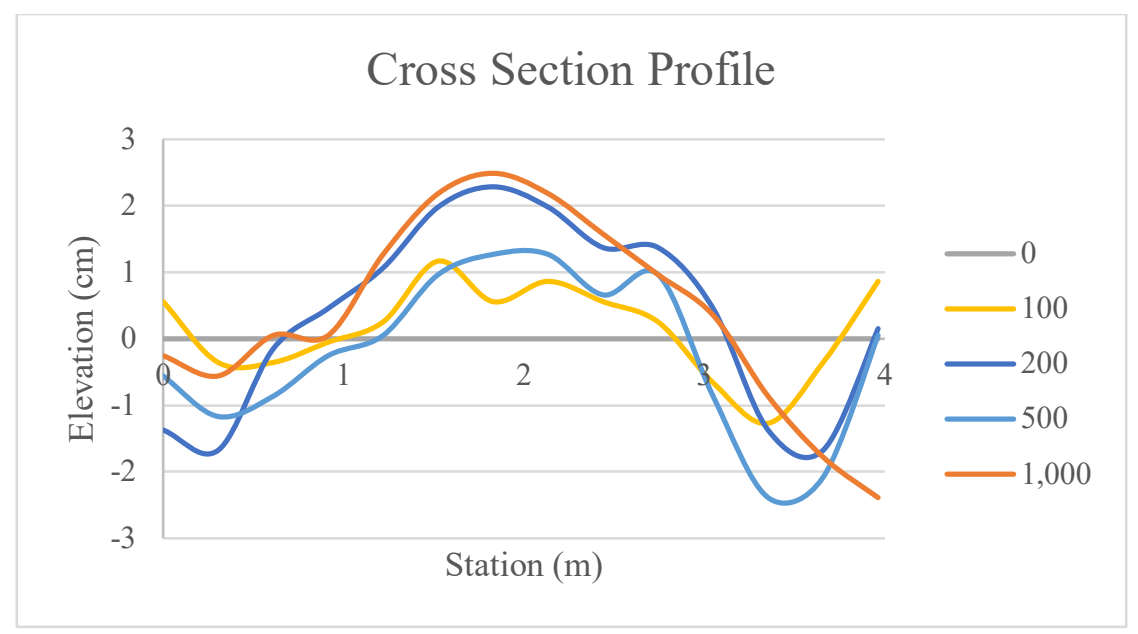

Figure 5. Representative cross section profile data for Fiberglass Matting 1 on sand..

The aluminum matting 1 on the sand test area did not experience any considerable elevation changes. The cross-section profile shows some rotation of the entire system during traffic testing. However, no rutting was observed. The matting successfully sustained 1,000 combined passes of vehicle traffic with no significant deformation or damage.

Longitudinal profile data for the thermoplastic matting show some upward and downward elevation changes along the length of the section. These changes approach $1.3 \mathrm{~cm}$ for both directions. While the entire system did not appear to deform with traffic, there was some faulting of the individual mats where the approach end would depress relative to the trailing end of the previous mat. These data likely reflect this characteristic of the system, although it had no detrimental effect on the performance. As with the other rigid systems, the cross section profile shows slight rotation of the mat system during traffic. However, no rutting occurred, and the mat successfully withstood 1,000 combined passes of vehicle traffic.

The cross section profile data for the aluminum matting 2 show that the system experienced a slight depression of over $1.3 \mathrm{~cm}$ in the longitudinal direction from around 8 to $11 \mathrm{~m}$. Otherwise, the mat system did not experience significant elevation changes. The cross section profile shows a slight rotation of the entire system during traffic testing, but no rutting was observed. The aluminum matting 2 successfully sustained 1,000 combined passes of vehicle traffic with no significant deformation or damage.

Cross section profile data for the fiberglass 2 matting on the sand test area show that the system experienced over $2.5 \mathrm{~cm}$ of permanent deformation along one end of the section and some upward elevation change along the opposite end. The cross section profile shows significant rutting in the wheel paths and upheaval in the center of the mat between the wheel paths and along the edges. These data show over $8 \mathrm{~cm}$ of total difference between the highest and lowest elevations. Overall, the fiberglass matting 2 successfully sustained 1,000 combined passes of vehicle traffic but was the poorest performer among the matting systems tested in terms of resistance to permanent deformation.

After all testing was completed, the sand was smoothed to its original condition and used as a control test item, and receiving 20 passes of the M1 with no matting. An average rut depth from 15 to $23 \mathrm{~cm}$ was observed upon completion.

\section{Medium-Strength Soil}

Due to time constraints, data were only collected at 500 combined traffic passes for aluminum matting 1 . The longitudinal profile data show that the system experienced some permanent deformation along the test area but mostly between 0 and $1.3 \mathrm{~cm}$. The cross section profile data show some slight rotation of the entire system during 
traffic testing. However, no rutting was observed. The aluminum matting 1 successfully sustained 500 combined passes of vehicle traffic with no significant deformation or damage.

Data were only collected at 500 combined traffic passes for aluminum matting 2 . The longitudinal profile data show significant scatter in the measured elevation with values ranging from 2.5 to $3.8 \mathrm{~cm}$ in somewhat of a wave-like pattern while the cross section data show the system remained relatively flat. Observations during the testing showed bending of the matting occurred during the traffic application, causing some areas to develop an uneven surface. The soil beneath the mat experienced some permanent deformation. While the aluminum matting 2 system withstood 500 combined traffic passes, some damage to the mat was observed. The damage did not prevent successful recovery of the mat onto the dispensing unit.

The thermoplastic matting was not tested on the medium-strength soil. Previous experience with this matting system has shown it exhibits no rutting or damage on this soil type, and time limitations prioritized traffic on other systems during the testing.

Cross section profile data for the fiberglass matting 1 on the medium-strength soil test area were taken at traffic intervals of 100 and 300 combined passes of the MTVR ( 90 percent) and M1 (10 percent). The cross section profile shows permanent deformations of $2.5 \mathrm{~cm}$ with little upheaval between the wheel paths. The mat was observed to have elastic properties that bridged the actual permanent deformation beneath it. Overall, the fiberglass matting 1 successfully sustained 300 combined passes of vehicle traffic. Due to time constraints, traffic was ceased at 300 passes.

For the fiberglass matting 2 system traffic included 100 combined passes and an additional 33 MTVR passes. Traffic ceased at this point since the damage to the mat severed it in many places and resulted in significant rutting. The longitudinal profile data show elevation changes in the mat ranging from 2.5 to $5 \mathrm{~cm}$ along the section. The cross section profile shows over $5 \mathrm{~cm}$ of permanent deformation in the wheel paths. Damage to the mat mostly consisted of tearing longitudinally along the wheel path as the rut depths became too great for the mat to bridge. The fiberglass matting 2 was unable to withstand the full traffic sequence over the medium-strength soil.

An untrafficked soil area was used as a control test item, receiving 50 passes of the M1 with no matting. An average rut depth from 28 to $36 \mathrm{~cm}$ was observed upon completion.

\section{Conclusions and Recommendations}

\section{Conclusions}

Results from this study provide an overall assessment of the attributes and capabilities of five different matting systems that can be used for site stability to enable ground vehicle maneuver. The ability to support ground vehicle maneuver was determined by operating a MTVR or CBT, each having a representative axle load and tire pressure, and an M1 Abrams, the Army's heaviest tracked vehicle, over the systems placed in a variety of soil strengths and slopes. Test conditions represent those that may be encountered in an expeditionary bridging scenario and encountered loose sand, medium-strength soil, marsh, and 10-percent and 25-percent grade slopes. Based on the results from this study, the following conclusions were developed.

- Fiberglass Matting 1 - This matting system is capable of providing adequate support over many soil types, but not those with extremely weak bearing capacity (1 to 2 CBR). Although not tested in the marsh area, the presence of approximately $2.5 \mathrm{~cm}$ of rutting in the medium-strength soil area with CBR greater than 8 , coupled with extensive experience with this system, indicates that Fiberglass matting 1 is not expected to spread loads well enough to meet the performance measures on the extremely weak soils.

- Aluminum Matting 1 - This matting system is capable of providing adequate support over all soil types included in this study. 
- Thermoplastic Matting - This matting system is capable of providing adequate support over all soil types included in this study.

- Aluminum Matting 2 - This matting system is capable of providing adequate support over all soil types included in this study.

- Fiberglass Matting 2 - this matting system is capable of providing adequate support over many soil types but not those with extremely weak bearing capacity (1-2 CBR). The matting was destroyed on the mediumstrength soil area after deep rutting developed. The total traffic count was 133 passes. Although not tested in the marsh area, the results from the medium-strength soil area suggest it would perform poorly over the extremely weak soil.

\section{Recommendations}

Based on the results from this study, commercial or government-owned matting systems exist that provide adequate military ground vehicle support over soft soils while meeting basic military transport requirements. If crossing extremely weak soils, it is recommended that a matting system similar to either the aluminum type or the thermoplastic be used to ensure adequate load distribution. For general soil types including sands and mediumstrength soils, the fiberglass matting is recommended. Other factors such as cost and material availability should be considered when selecting an appropriate matting system.

\section{References}

Harder, Daniel E. and John F. Rushing. 2018. Site Stabilization for the Improved Ribbon Bridge (IRB) Bridge Supplementary Set (BSS). ERDC/GSL TR-18-9. Vicksburg, MS: U.S. Army Engineer Research and Development Center.

Floyd, Webster C. 2017. Evaluation of the WavTrac expeditionary mobility matting system. ERDC/GSL TR-17-4. Vicksburg, MS: U.S. Army Engineer Research and Development Center.

Rushing, Todd S., Jeb S. Tingle, and Quint S. Mason. 2007. Evaluation of expeditionary mat surfacings for beach roads. ERDC/GSL TR-07-16. Vicksburg, MS: U.S. Army Engineer Research and Development Center.

Rushing, Timothy W., and James F. Rowland. 2012. Comparison of original MO-Mat and prototype replicas for expeditionary roads. ERDC/GSL TR-12-18. Vicksburg, MS: U.S. Army Engineer Research and Development Center.

Rushing, Timothy W., Jeb S Tingle, Timothy J. McCaffrey, and Todd S. Rushing. 2009. Evaluation of Supa-Trac matting for expeditionary roads. ERDC/GSL TR-09-24. Vicksburg, MS: U.S. Army Engineer Research and Development Center.

Rushing, Timothy W., and Nalina Torres. 2007. Prototype mat system evaluation. ERDC/GSL TR-09-29. Vicksburg, MS: U.S Army Engineer Research and Development Center.

Santoni, Rosa L., Carroll J. Smith, Jeb S. Tingle, and Steve L. Webster. 2001. Expedient road construction over soft soils. ERDC/GSL TR-01-7. Vicksburg, MS: U.S. Army Engineer Research and Development Center. 


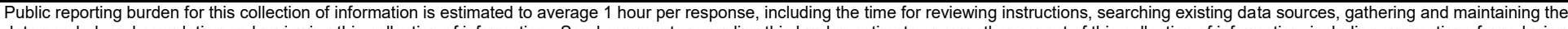

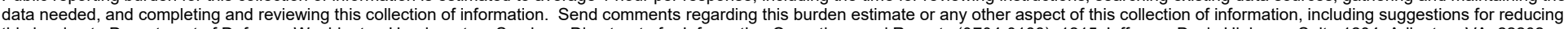

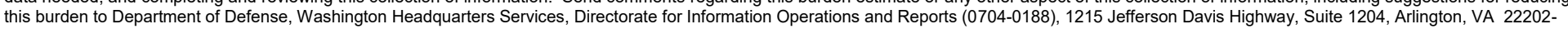

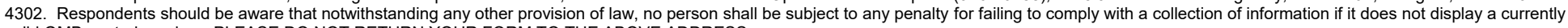
valid OMB control number. PLEASE DO NOT RETURN YOUR FORM TO THE ABOVE ADDRESS.

$\begin{aligned} & \text { 1. REPORT DATE (DD-MM-YYYY) } \\ & \text { April } 2020\end{aligned}$
$\begin{aligned} & \text { 2. REPORT TYPE } \\ & \text { 4. TITLE AND SUBTITLE }\end{aligned}$

\section{TITLE AND SUBTITLE}

Improved Vehicle Mobility by Using Terrain Surfacing Systems

3. DATES COVERED (From - To)

5a. CONTRACT NUMBER

5b. GRANT NUMBER

5c. PROGRAM ELEMENT NUMBER

0603119A

6. AUTHOR(S)

5d. PROJECT NUMBER

BL8

5e. TASK NUMBER

John F. Rushing and Daniel E. Harder

5f. WORK UNIT NUMBER

7. PERFORMING ORGANIZATION NAME(S) AND ADDRESS(ES)

8. PERFORMING ORGANIZATION REPORT NUMBER

U.S. Army Engineer Research and Development Center (ERDC)

Geotechnical and Structures Laboratory

ERDC/GSL MP-20-1

3909 Halls Ferry Road

Vicksburg, MS 39180

\section{SPONSORING / MONITORING AGENCY NAME(S) AND ADDRESS(ES)}

U.S. Army, Washington, DC
10. SPONSOR/MONITOR'S ACRONYM(S)

11. SPONSOR/MONITOR'S REPORT NUMBER(S)

\section{DISTRIBUTION / AVAILABILITY STATEMENT}

Approved for public release; distribution is unlimited.

\section{SUPPLEMENTARY NOTES}

Originally published as proceeding of 15th ISTVS European-African Regional Conference 2019.

\section{ABSTRACT}

Even for military vehicles designed with superior off-road capabilities, problematic soil conditions can impede mobility, particularly when many vehicles need to traverse the same path. Loose sands with little shear strength or wet silts or clays with little bearing capacity can deform rapidly under traffic. U.S. Army Engineer Research and Development Center researchers conducted field testing over several terrain conditions to measure performance of terrain surfacing systems designed to improve vehicle mobility. Soil conditions included poorly-graded sand, medium-strength silt, weak marsh, and two different slope conditions. Five different terrain surfacing, or matting systems, were tested that included four commercial variants and one U.S. government design. All testing took place at the ERDC Ground Vehicle Terrain Surfacing Test Facility in Vicksburg, Mississippi. Military test vehicles included a Marine Tactical Vehicle Replacement, Common Bridge Transporter, and M1 Abrams tank. Results from the testing showed that all matting systems provided notable improvement in the number of allowable vehicle passes over soft sands. Results varied for the different systems over weaker soils, with performance improved for those matting systems having thicker and stiffer panels. However, improved performance among matting systems came with a sacrifice of increased logistical burden. Data presented here-in include detailed site characteristics and soil deformation as a function of traffic.

\section{SUBJECT TERMS}

Terrain surfacing, matting, site stability, mobility

16. SECURITY CLASSIFICATION OF:

\section{a. REPORT}

Unclassified

\section{b. ABSTRACT}

Unclassified c. THIS PAGE

Unclassified

17. LIMITATION
OF ABSTRACT
UU

18. NUMBER OF PAGES

20 19a. NAME OF RESPONSIBLE PERSON 19b. TELEPHONE NUMBER 